DOI: $10.4274 /$ jarem.galenos.2021.73792

J Acad Res Med 2021;11(2):211-8

\title{
Comparison of Enteropathogens in Hospitalized Children with Acute Gastroenteritis
}

\author{
(1) Merve Arslan1, (1) Melike Mercan Başpınar1, (1) Seda Geylani Güleç2, (1) Okcan Basat1 \\ ${ }^{1}$ University of Health Sciences Turkey, Gaziosmanpaşa Training and Research Hospital, Clinic of Family Medicine, İstanbul, Turkey \\ 2University of Health Sciences Turkey, Gaziosmanpaşa Training and Research Hospital, Clinic of Pediatrics, İstanbul, Turkey
}

Cite this article as: Arslan M, Başpınar MM, Geylani Güleç S, Basat O. Comparison of Enteropathogens in Hospitalized Children with Acute Gastroenteritis. J Acad Res Med 2021;11(2):211-8

\begin{abstract}
Objective: This study aimed to compare enteropathogens in children with acute gastroenteritis (AGE) and evaluate their rotavirus (RV) immunization, length of hospitalization, and clinical severity by Ruuska-Vesikari clinical scoring system.

Methods: A retrospective data-based study including 642 hospitalized children with AGE aged between 1 month and 18 years who were admitted to the pediatrics department of a tertiary care hospital from 2014 to 2018.

Results: RV vaccination was not reported in any of the patients. Of the 642 patients hospitalized for AGE, cases included 179 RV enteritis (27.9\%), 22 adenovirus enteritis (3.4\%), 14 Entamoeba histolytica enteritis (2.2\%), 11 Giardia enteritis (1.7\%), and 413 unidentified pathogens (64\%). The RuuskaVesikari score was not correlated to the length of hospitalization $(p=0.31 ; r=0.04)$. RV enteritis was higher in the winter season (26.8\%) and in April (16.8\%) than at other times. Most common age range of the RV cases (36.9\%) were between 12 and 24 months. The clinical severity of children with AGE was classified as a mild, moderate, and severe (14.5\%,35.5\%, and 50\%), respectively. About $73.2 \%$ of RV cases had severe disease (RuuskaVesikari score 211$)$ and had a higher score than other pathogens $(p<0.001)$.

Conclusion: In this study, RV was the most identified AGE pathogen among hospitalized children without RV vaccination. Future studies comparing AGE cases with or without RV immunization would be helpful for health policies.
\end{abstract}

Keywords: Diarrhea, gastroenteritis, pediatrics, rotavirus, Ruuska-Vesikari score

\section{INTRODUCTION}

In Turkey, among 117,741 children with diarrhea, there were 26,566 children with rotavirus (RV) gastroenteritis (31.8\%) based on the 98 studies published from 1987-2016 (available at https://www.who.int/news-room/fact-sheets/detail/diarrhoealdisease). In 2013, the World Health Organization recommended all countries to introduce RV vaccines into their national immunization program, after which there were dramatic reductions in clinical visits, hospitalization, and RV-associated deaths in most of the countries (available at: https://apps.who. int/iris/handle/10665/331323). Changes in acute gastroenteritis (AGE) hospitalization during RV seasons before and after the universal mass vaccination at Estonia (2014) showed a reduction in overall AGE accompanied by a decrease in the infection severity among the hospitalized children (1). Although the expanded immunization program against the 13 diseases in childhood is done free of charge, mainly by the family physicians in Turkey, the RV vaccine was not introduced into the national free immunization program (2). Changes in sociodemographic factors (immigration, wars, etc.), sanitation problems, and inadequate immunization rates may affect future health policies.

ORCID IDs of the authors: M.A. 0000-0001-8452-6381; M.M.B. 0000-0003-3183-3438; S.G.G. 0000-0002-6402-2175; O.B 0000-0002-5222-9136. 
This retrospective study aimed to describe enteropathogens among hospitalized children with AGE, the prevalence of RV vaccination, the length of the hospital stay, and the clinical severity by the Ruuska-Vesikari score.

\section{METHODS}

We retrospectively analyzed hospitalization data of 4 years which were associated with AGE in the pediatrics department of a training and research hospital from January 1, 2014 to January 1, 2018. The demographic and clinical data of 642 hospitalized children with AGE aged between 1 month and 18 years old were analyzed. Informed consent of the patients was obtained from the parents. Taksim Training and Research Hospital's Clinical Research Ethics Committee approved this study on March 21, 2018 (approval no: 34).

This study assumed that the patients who were hospitalized with AGE or diarrhea had the occurrence of three or more loose or liquid stools per day. We excluded children from this study if i) children had chronic diarrhea or have another disease that might have caused chronic diarrhea ii) children had a factor that might have negatively affected the length of hospitalization, such as immunodeficiency, malnutrition, or multiple malformations iii) patients who did not have a stool test result iv) newborn babies ( $<1$ month of age). Laboratory markers were measured in patients' peripheral blood on the first day of hospitalization. Stool samples were collected from each child for enteropathogen analysis, stool culture, measurement of occult blood, and leukocytes.

Seven scoring parameters in Ruuska-Vesikari clinical severity scoring system consider each of the symptoms identified: diarrhea, vomiting, fever, dehydration, the duration of diarrhea, and vomiting. Treatment status is considered as an additional parameter. Each of the seven parameters is broken into thirds according to an equally divided severity distribution as identified by Ruuska and Vesikari (3) in 1990. The scores for each parameter within the clinical severity scoring system are added, allowing for a severity score between 0 and 20 points. Severity scores $\geq 11$ are considered severe, scores between 7 and 10 are considered moderate, and scores $<7$ are considered mild (3).

\section{Statistical Analysis}

Data were analyzed by the IBM SPSS Statistics 22 program (SPSS IBM, Turkey). Normality control of the data distribution was performed by the Shapiro-Wilk test and the KolmogorovSmirnov test. Results were calculated as the mean, median, frequency, and percentage. Kruskal-Wallis test was used to compare enteropathogenic groups and numeric variables, chisquare test was used to compare enteropathogenic groups and categorical variables, and Spearman's rho correlation test was used to analyze the relationship between the length of hospitalization and Ruuska-Vesikari score.

\section{RESULTS}

Out of 642 patients, 380 (59\%) were male, and and 262 (41\%) were female. The mean age was 2.4 years. Enteropathogens were identified in 229 (46.7\%) of 642 patients. Agents were RV in 179 (27.9\%) patients, adenovirus in 22 (3.4\%) patients, Entamoeba histolytica in 14 (2.2\%) patients, Giardia in 11 of 642 (1.7\%) patients, mix type (RV plus adenovirus) in $3(0.5 \%)$ patients and unidentified pathogens in 413 (64.3\%) patients. RV was present in in $78 \%(179 / 229)$ of all the identified AGE cases, and nearly $40 \%$ (71/179) occurred in patients $<12$ months of age. Table 1 shows the comparison of pathogens based on hospital stay, Ruuska-Vesikari score, age, gender, seasonality, and hospitalization period. The RV group (36.9\%) had a higher presence than other pathogens with a longer hospital stay than the adenovirus and unidentified groups ( $p=0.00$ and $p=0.002$, respectively). The Ruuska-Vesikari score was $10.4 \pm 3.2$, which was significantly different among the pathogen types $(p<0.001)$. The RV group had a higher Vesikari score than others $(p<0.001)$.

A total of 149 cases in 2017, 222 cases in 2016, 170 cases in 2015, and 101 cases in 2014 were hospitalized for gastroenteritis. Regarding the seasonal and monthly distribution of the AGE cases, the highest AGE approval number was in the summer season $(29.6 \%, 190$ cases), especially in the month of May $(12.3 \%$, 79 cases).

Although it was not significant ( $p=0.837$ ), as seen in Figure 1, boys had a higher AGE rate than that of girls, except for $E$. histolytica in summer (100\% female) and adenovirus in autumn (66.7\% female).

The highest RV cases were observed in spring, especially in April and May, but the statistical difference was observed in the winter $(p<0.001)$. The seasonal rate of RV $(26.8 \%)$ in the winter was higher than that of adenovirus (13.6\%), unidentified types (17.9\%), E. histolytica (7.1\%), and Giardia (18.2\%) with $p=0.010, p<0.001$, $p<0.001$, and $p=0.003$ values, respectively.

As seen in Figure 2, the AGE rate of RV was highest in April (16.8\%) and significantly higher than that of other pathogens.

Dehydration was mild in $62.9 \%$, moderate in $36.1 \%$, and heavy in $0.9 \%$ of all patients. Table 2 shows the comparison of pathogens based on fever, dehydration, and clinical severity. In the comparison of fever (body temperature, 38-38.4 $4^{\circ}$ between pathogens, the E. histolytica group (42.9\%) had significantly higher rates than RV (10.1\%), adenovirus (4.5\%), giardia (\%9.1) and unidentified type (10.7\%) groups ( $p=0.001, p=0.002, p<0.001$ and $p<0.001$, respectively.

In the comparison of RV positive (20.4\%) and negative (15.7\%) $A G E$, we found a significant difference in moderate dehydration for RV $(p<0.001)$. There was no difference for mild or severe dehydration. As seen in Table 2, 87.2\% of RV cases were of high clinical severity. Table 3 shows the evaluation of diarrhea and vomiting in AGE based on enteropathogen types. The duration of diarrhea among $76 \%$ of cases was 1-4 days long, while the 
There was a difference among the pathogen groups regarding vomiting frequency and duration $(p<0.001)$. The duration of vomiting 2 days long was significantly lower in the unidentified type group (12.3\%), than in the RV (31.3\%), adenovirus (31.8\%), E. histolytica group (14.3\%) and Giardia (45.5\%) groups ( $p<0.001$, $p<0.001, p<0.001$ and $p=0.009$, respectively). Vomiting frequency $>3$ times a day was significantly higher in the E. histolytica group (28.6\%) than in the RV (46.9\%) and adenovirus (50\%) groups $(p<0.001, p=0.037)$. Vomiting frequency 5 times a day was respectively).

Table 1. Comparison of pathogens based on hospital stay (day), Ruuska-Vesikari score, age, gender, seasonality, and hospitalization periods (month/year)

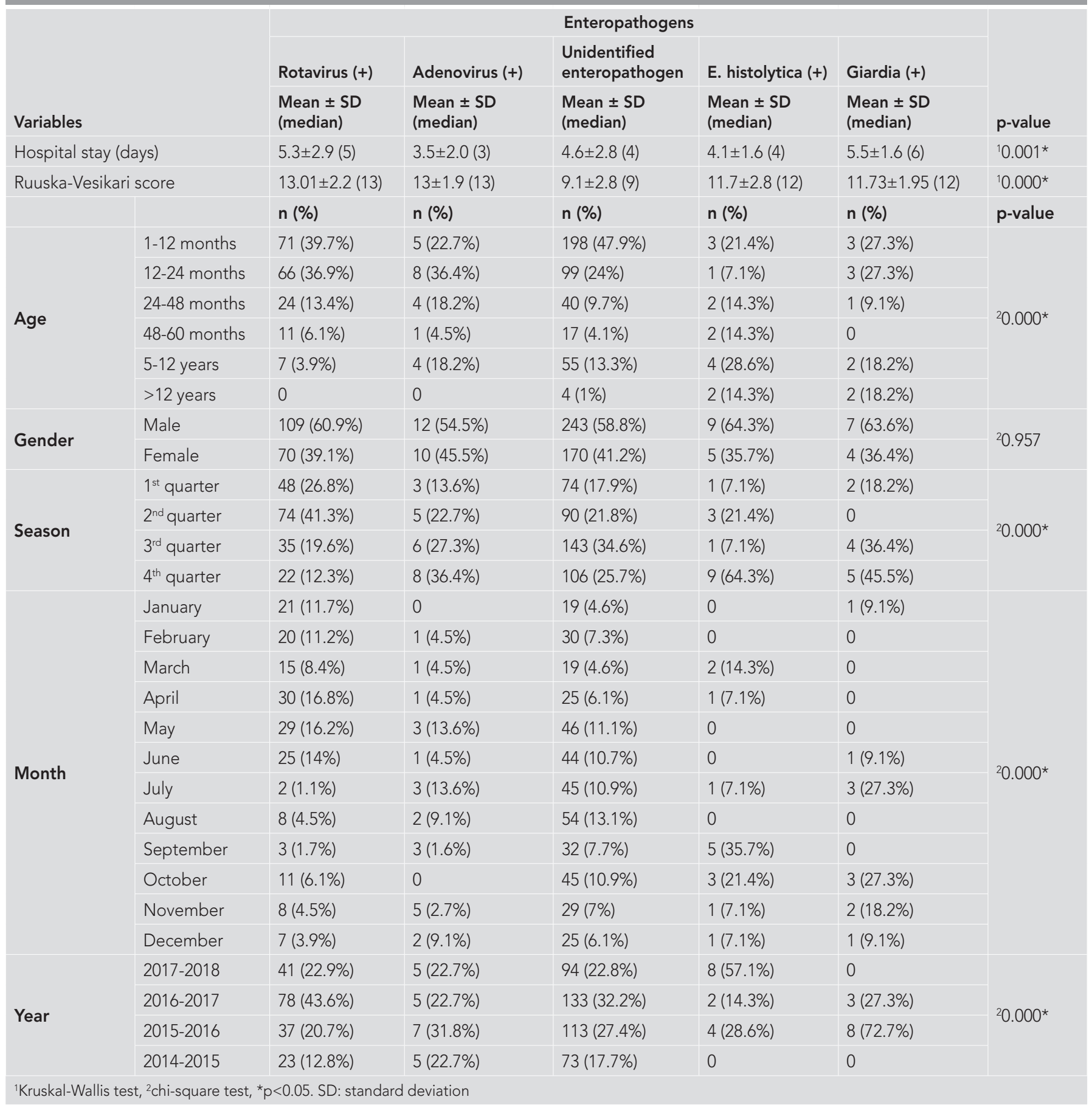


significantly higher in the E. histolytica group (42.9\%) than in the RV (36.3\%), adenovirus (36.4\%), and Giardia (27.3\%) groups $(p<0.00, p=0.003$, and $p=0.020$, respectively).

Additional symptoms were reported (13.4\% RV, $15.7 \%$ unidentified, 28.6\% E. histolytica, and 18.2\% Giardia). Hepatic transaminases [alanine transaminase (ALT), aspartate transaminase (AST)] were higher in the RV group (10.6\%) than with the other enteropathogens $(9.1 \%$ Giardia, $7.3 \%$ unidentified, $4 \%$ adenovirus). The rate of rashes in the $\mathrm{E}$. histolytica group was $21.4 \%$ (1.1\% RV, $2.9 \%$ unidentified), which was significantly higher than that with other pathogens $(p<0.001 ; p<0.001)$. At the same time, one appendicitis case in patients with giardia enteritis, two invagination cases in $\mathrm{RV}$ group, one invagination case in E. histolytica group, 13 convulsion cases in unidentified group were detected.

Enteropathogens and hospital stay were evaluated based on the season and Ruuska-Vesikari score (Figure 3). RV and unidentified enteropathogens were the most common reasons for hospital stay. The mean hospital stay was 4.7 (2.8) days, and the RV positive group had a longer stay than that of the RV negative cases $(p=0.01)$. RV had a higher RuuskaVesikari score and hospitalization time both in winter and spring at a high rate. There was no relationship between Ruuska-Vesikari score and hospital stay in the AGE cases $(p=0.312, r=0.04)$.

\section{DISCUSSION}

The most striking part of this retrospective analysis was that no children with AGE had RV immunization before, and RV enteritis had a longer length of hospital stay and clinical severity than other enteropathogens.

The presence of RV was reported to be $7.8-41 \%$ in Turkey $(4,5)$. High presence of RV has been reported in the literature in Canada (71.7\%), China (68.7\%), South Korea (66.7\%), and Saudi Arabia (50\%) (6-9). The presence of RV in our study was $27.9 \%$, similar to that reported in Turkey.

In a study from Saudi Arabia, $69.6 \%$ of cases were $<12$ months of age, and there was a dramatic decline in the incidence of RV positive diarrhea after the age of 1 year (9). Similarly, 96\% of children with RV enteritis and $88 \%$ of all AGE cases were $<5$ years of age in our study. Around $40 \%$ of all RV cases were $<12$ months of age, and the RV phrequency (36.9\%) was significantly higher than other AGE groups aged between 12-24 months.

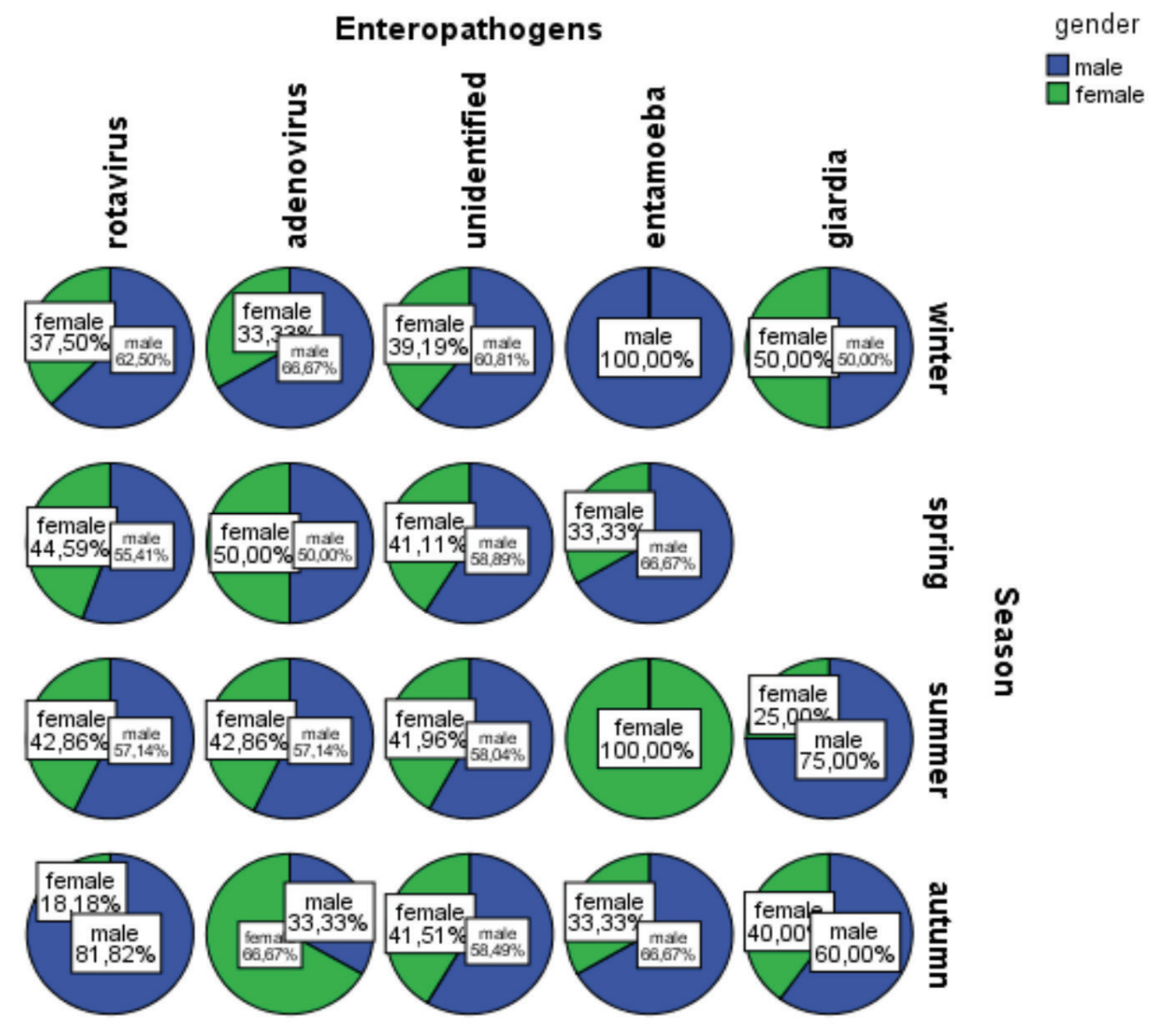

Figure 1. Evaluation of enteropathogens and seasonal rates based on gender 
In a study by Salami et al. (10), E. histolytica was the leading enteropathogen in $27.8 \%$ of cases, followed by RV, adenovirus, and mixed group (two or more identified enteropathogens) with $13.6 \%, 6.1 \%$, and $6.1 \%$, respectively. Around $96 \%$ of cases were classified as unidentified enteropathogens. This might have been caused by the absence of advanced bacterial diagnosis and the lack of detection of some viruses (astrovirus

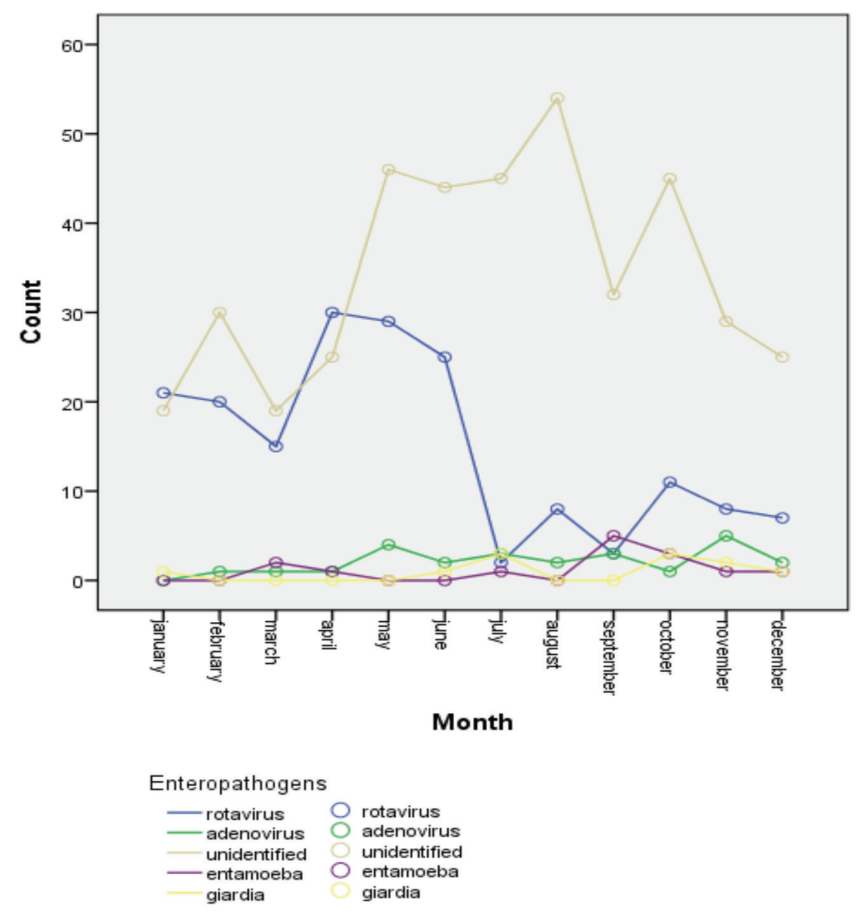

Figure 2. Evaluation of enteropathogens and monthly rates

Table 2. Comparison of enteropathogens based on body fever, dehydration, and clinical severity of gastroenteritis

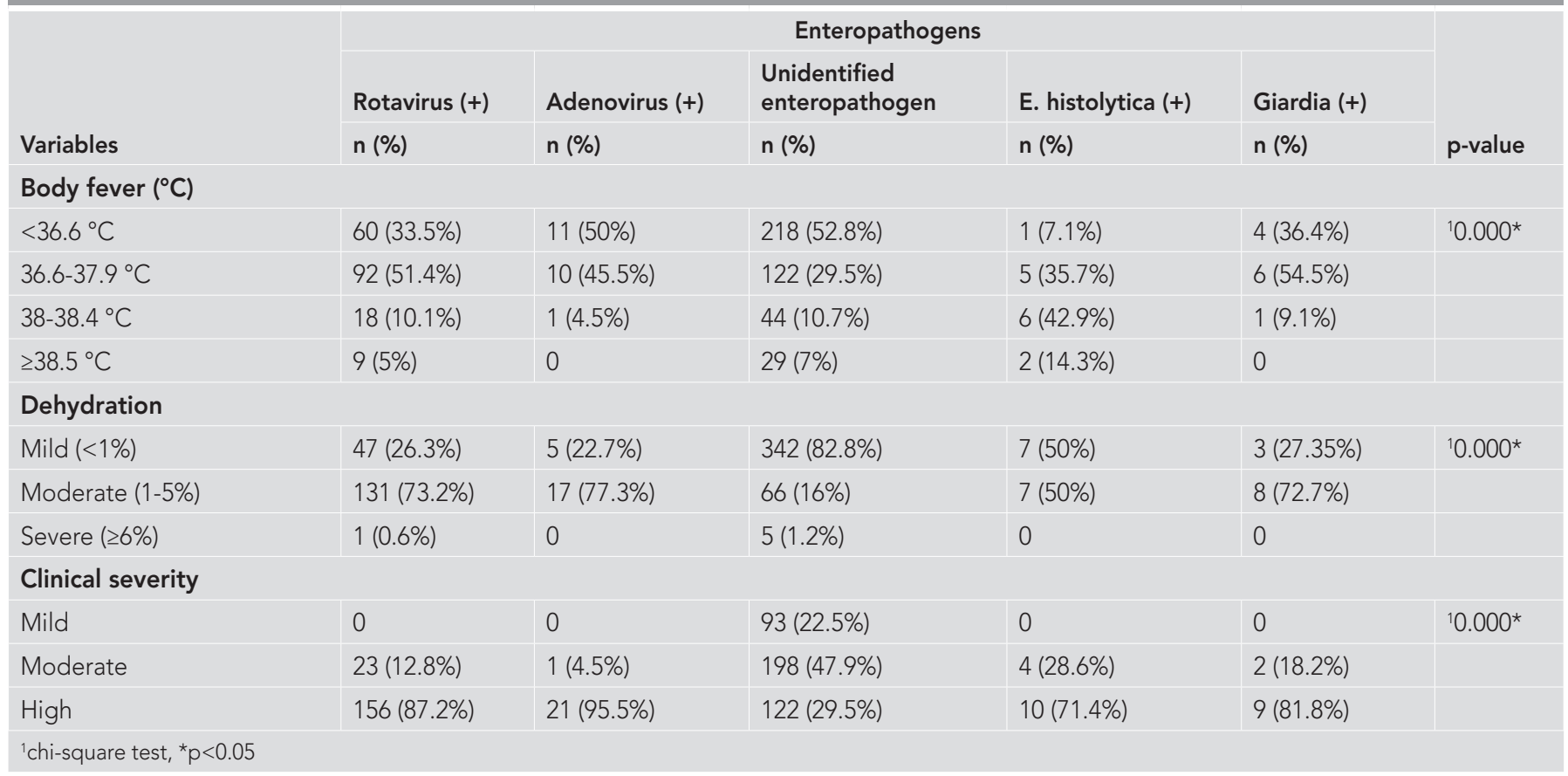

and norovirus), as in our study. In our study, the unidentified enteropathogen had the highest ratio. We thought that this might have been due to factors that cause diarrhea, such as additional food. More frequent diarrhea in children <48-60 months may be associated with additional foods beginning in the sixth month. Because of the humoral and cellular antiinfective properties of human milk, breast milk protects babies against diarrhea (11).

In France, RV infections mostly occur during the winter and spring seasons, with a peak between January and April (12). Before vaccine introduction (2002-2006), RV-coded hospitalizations in New York City were elevated during each winter, with epidemics typically beginning in January, peaking in March, and declining by May (13). In our study, the seasonal rate of RV was higher in winter, peaked in April, and declined by July. We thought the difference in comparison of months might have originated from the the climate zone of our country. For example, more RV cases were observed during the spring and summer in a Saudi Arabian study (9).

Diarrhea in children living in Turkey is observed most commonly in the eastern region. A study showed that the prevalence of diarrhea is 1,581-fold higher in rural, rural-to-urban, and urbanto-rural children compared to urban children and that internal migration was observed to increase the frequency of diarrhea (14). In our study, the RV rate in 2016 was significantly higher than that of other years.

Simultaneously, the hospital's location might have been another reason, because it receives high internal immigration from low socio-economic regions. We thought that increased AGE cases in our hospital during 2016 would depend on 


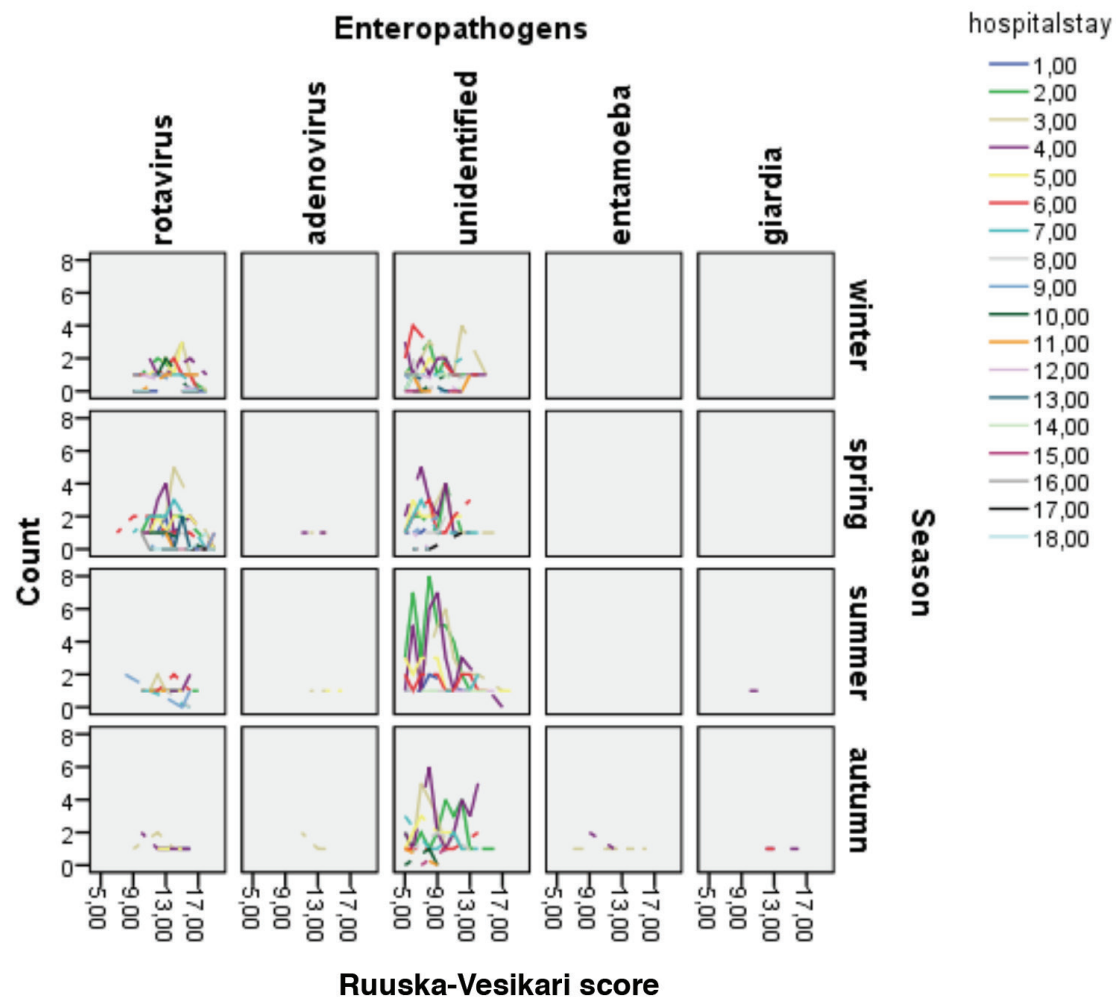

Figure 3. Evaluation of enteropathogens and hospital stay based on season and Ruuska-Vesikari score

Table 3. Evaluation of diarrhea and vomiting according to enteropathogen type

\begin{tabular}{|c|c|c|c|c|c|c|}
\hline \multirow{3}{*}{ Variables } & \multicolumn{5}{|c|}{ Enteropathogens } & \multirow[b]{3}{*}{$p$-value } \\
\hline & \multirow{2}{*}{$\begin{array}{l}\text { Rotavirus (+) } \\
\text { n (\%) }\end{array}$} & \multirow{2}{*}{$\begin{array}{l}\text { Adenovirus (+) } \\
\mathrm{n}(\%)\end{array}$} & \multirow{2}{*}{$\begin{array}{l}\text { Unidentified } \\
\text { enteropathogen } \\
n(\%)\end{array}$} & \multirow{2}{*}{$\begin{array}{l}\text { E. histolytica (+) } \\
n(\%)\end{array}$} & \multirow{2}{*}{$\begin{array}{l}\text { Giardia (+) } \\
\text { n (\%) }\end{array}$} & \\
\hline & & & & & & \\
\hline \multicolumn{7}{|c|}{ Duration of diarrhea } \\
\hline 1-4 days & 118 (65.9\%) & $12(54.5 \%)$ & $338(81.8 \%)$ & $11(78.6 \%)$ & $9(81.8 \%)$ & ${ }^{1} 0.000 *$ \\
\hline 5 days & $25(14 \%)$ & $5(22.7 \%)$ & $15(3.6 \%)$ & $1(7.1 \%)$ & 0 & \\
\hline \multicolumn{7}{|c|}{ Episodes of diarrhea } \\
\hline 1-3 times & $16(8.9 \%)$ & 0 & 217 (52.5\%) & $2(14.3 \%)$ & $2(18.2 \%)$ & ${ }^{1} 0.000 *$ \\
\hline 4-5 times & 78 (43.6\%) & $12(54.5 \%)$ & $115(27.8 \%)$ & $5(35.7 \%)$ & $6(54.5 \%)$ & \\
\hline$\geq 6$ times & $85(47.5 \%)$ & $10(45.5 \%)$ & $81(19.6 \%)$ & $7(50 \%)$ & $3(27.3 \%)$ & \\
\hline 2 days & $56(31.3 \%)$ & $7(31.8 \%)$ & 51 (12.3\%) & $2(14.3 \%)$ & $5(45.5 \%)$ & \\
\hline$\geq 3$ days & $84(46.9 \%)$ & $11(50 \%)$ & $82(19.9 \%)$ & $4(28.6 \%)$ & $2(18.2 \%)$ & \\
\hline \multicolumn{7}{|c|}{ Episodes of vomiting (maximum number/day) } \\
\hline No times & $4(2.2 \%)$ & $1(4.5 \%)$ & $166(40.2 \%)$ & $6(42.9 \%)$ & $1(9.1 \%)$ & ${ }^{1} 0.000^{*}$ \\
\hline 1 time & $9(5 \%)$ & 0 & $71(17.2 \%)$ & $1(7.1 \%)$ & 0 & \\
\hline 2-4 times & $101(56.4 \%)$ & $13(59.1 \%)$ & 144 (34.9\%) & $1(7.1 \%)$ & 7 (63.6\%) & \\
\hline$\geq 5$ times & 65 (36.3\%) & $8(36.4 \%)$ & $32(7.7 \%)$ & $6(42.9 \%)$ & $3(27.3 \%)$ & \\
\hline${ }^{1}$ chi-square test & & & & & & \\
\hline
\end{tabular}


increased applies based on Syrian refugees living near the hospital location.

RV has been reported to be associated with encephalopathy, myositis, and elevated hepatic transaminases, and even simultaneous presentation of all these conditions was published in a case report of a 17-month-old girl (hypernatremia, encephalopathy, myositis, transaminitis, and hypoalbuminemia) (15). In a study by Teitelbaum and Daghistani (16), 20\% of children had elevated ALT and AST (16). In our study, the rate of elevated hepatic transaminase was $10.6 \%$ in cases of RV, $9.1 \%$ in cases of Giardia, and $7.3 \%$ in cases of of unidentified gastroenteritis.

A study by Ogawa et al. (17) reported that RV infection is a risk factor for splenic lesions in patients with benign convulsions having mild gastroenteritis, suggesting that RV causes edema in the corpus callosum. We found 14 cases (2.2\%) with convulsion symptoms who already had a febrile convulsion history in 4 patients, but magnetic resonance of patients had no specific results.

Concerning viral pathogens in a study on appendicitis etiology by Richardsen et al. (18), adenovirus was the most common with an incidence of $5.4 \%$, followed by RV (4.7\%). In our study, appendicitis developed in one case, caused by Giardia.

The rate of rashes in the E. histolytica group was $21.4 \%$ (1.1\% $\mathrm{RV}, 2.9 \%$ unidentified), which was significantly higher than other pathogens. We thought that the high rash rate in E. histolytica might have resulted from the fever reaction, because the E. histolytica group's fever rate was significantly higher than that of other pathogens.

\section{Study Limitations}

Firstly, as we started this study, our goal was to descriptively analyze children with AGE and compare groups with or without the $R V$ vaccine. However, we found that no child was vaccinated in our study sample. We thought that this might have been due to the vaccine fee, insufficient level of knowledge about vaccination, or socio-economic factors. Secondly, the retrospective study design did not permit us to ask parents about some demographic variables (such as using the hand for oral feeding, living in a large family, socio-economic level, maternal education level, disposal methods of children's feces, source of water, etc.) that would negatively affect sanitation and hygiene. Thirdly, the norovirus detection kit was absent in our hospital laboratory, which might have been responsible for the high presence of unidentified pathogens.

\section{CONCLUSION}

This retrospective study demonstrated that the highest ratio of identified enteropathogens of AGE in hospitalized children belonged to $\mathrm{RV}$, of which all cases had not received $\mathrm{RV}$ vaccination. We described that RV may cause severe complications with severe gastroenteritis and highlighted the importance of RV vaccination in the national immunization program, which may prevent long hospital stays.

Ethics Committee Approval: Taksim Training and Research Hospital's Clinical Research Ethics Committee approved this study on March 21, 2018 (approval no: 34)

Informed Consent: Informed consent of the patients was obtained from the parents.

Peer-review: Internally peer-reviewed.

Author Contributions: Concept - M.A., M.M.B., S.G.G., O.B.; Design M.A., M.M.B., S.G.G., O.B.; Data Collection and/or Processing - M.A., M.M.B.; Analysis and/or Interpretation - M.A., M.M.B., S.G.G., O.B.; Literature Search - M.A., M.M.B., S.G.G., O.B.; Writing - M.A., M.M.B., S.G.G., O.B.

Conflict of Interest: The authors have no conflict of interest to declare.

Financial Disclosure: The authors declared that this study has received no financial support.

\section{REFERENCES}

1. Kõivumägi K, Toompere K, Soeorg H, Kallas E, Jõgeda E-L, Huik K, et al. Acute gastroenteritis hospitalizations after implementation of universal mass vaccination against rotavirus. Vaccine 2020; 38: 287986

2. TC Sağlık Bakanlığı Sağlık İstatistikleri Yıllığı, Sağlık Araştırmaları Genel Müdürlüğü Ankara. 2016: 181-209. Available from: https://www.saglik. gov.tr/TR,31249/saglik-istatistikleri-yilligi-2016-yayinlanmistir.html

3. Ruuska T, Vesikari T. Rotavirus disease in Finnish children: use of numerical scores for clinical severity of diarrhoeal episodes. Scand J Infect Dis 1990; 22: 259-67

4. Ulukanlıgil M, Bakır M, Arslan G, Soran M, Seyrek A. Şanlıurfa'da 0-5 yas arası çocuklarda ishal etkenlerinin araştııılması. Mikrobiyoloji Bülteni 2001; 35: 307-12.

5. Gültepe B, Yaman G, Çıkman A, Güdücüoğlu H. Çocukluk yaş grubu gastroenteritlerde rotavirus ve adenovirus sıklığı. Türk Mikrobiyol Cem Derg 2012; 42: 16-20.

6. Rivest P, ProulX M, Lonergan G, Lebel MH, Bédard L. Hospitalisations for gastroenteritis: the role of rotavirus. Vaccine 2004; 22: 2013-7.

7. Huh J-W, Kim W-H, Moon S-G, Lee J-B, Lim Y-H. Viral etiology and incidence associated with acute gastroenteritis in a 5-year survey in Gyeonggi province, South Korea. J Clin Virol 2009; 44: 152-6.

8. Zhang S, Chen TH, Wang J, Dong C, Pan J, Moe C, et al. Symptomatic and asymptomatic infections of rotavirus, norovirus, and adenovirus among hospitalized children in Xi'an, China. J Med Virol 2011; 83: 1476-84.

9. Nahari A, AlGhamdi SM, Alawfi A, Faqeehi H, Alzahrani S, Abu-Shaheen A, et al. The clinical burden of rotavirus gastroenteritis: a prospective study. Cureus 2017; 9: e1903. doi: 10.7759/cureus.1903.

10. Salami A, Fakih H, Chakkour M, Salloum L, Bahmad HF, Ghssein G. Prevalence, risk factors and seasonal variations of different Enteropathogens in Lebanese hospitalized children with acute gastroenteritis. BMC Pediatr 2019; 19: 137

11. Popkin BM, Adair L, Akin JS, Black R, Briscoe J, Flieger W. Breast-feeding and diarrheal morbidity. Pediatrics 1990; 86: 874-82.

12. De Rougemont A, Kaplon J, Fremy C, Legrand-Guillien M-C, MinouiTran A, Payan C, et al. Clinical severity and molecular characteristics of circulating and emerging rotaviruses in young children attending hospital emergency departments in France. Clin Microbiol Infect 2016; 22: 737. e9-15. doi: 10.1016/j.cmi.2016.05.025

13. Olson DR, Lopman BA, Konty KJ, Mathes RW, Papadouka V, Ternier A, et al. Surveillance data confirm multiyear predictions of rotavirus dynamics in New York City. Sci Adv 2020; 6 :eaax0586. doi: 10.1126/sciadv.aax0586.

14. Şantaş G. Türkiye'de iç göçün beş yaş altı çocuklarda ölümlülük ve ishal üzerindeki etkisine ilişkin bir araştırma. Celal Bayar Üniversitesi Sağlık Bilimleri Enstitüsü Dergisi 2018; 5: 199-208.

15. Trivedi M, Jain A, Shah D, Gupta P. Rotavirus Gastroenteritis associated with encephalopathy, myositis, transaminitis and hypoalbuminemia. Indian J Pediatr 2019; 86: 642-4. 
16. Teitelbaum JE, Daghistani R. Rotavirus causes hepatic transaminase elevation. Dig Dis Sci 2007; 52: 3396-8.

17. Ogawa C, Kidokoro H, Ishihara N, Tsuji T, Kurahashi H, Hattori A, et al. Splenial lesions in benign convulsions with gastroenteritis associated with rotavirus infection. Pediatr Neurol 2020; 109: 79-84.
18. Richardsen I, Schöb D, Ulmer T, Steinau G, Neumann U, Klink C et al. Etiology of appendicitis in children: the role of bacterial and viral pathogens. Journal of Investigative Surgery 2016; 29: 74-9. 